\title{
Educomunicação: proporcionando ações formativas para educação integral
}

\section{Educommunication: providing training actions for integral education}

\section{Educomunicación: acciones formativas para la educación integral}

\begin{abstract}
Kelinne de Oliveira Guimarães
Jornalista do Instituto Federal do Tocantins (IFTO), mestranda do Programa de Educação Profissional Tecnológica (Profept) - Instituto Federal do Tocantins -

Campus Palmas - IFTO - TO - Brasil

https://orcid.org/0000-0001-8381-9190
\end{abstract}

\begin{abstract}
Weimar Silva Castilho
Docente do Instituto Federal do Tocantins (IFTO), professor do Programa de Mestrado em Educação profissional Tecnológica, doutor em Sistemas Mecatrônicos pela Universidade de Brasília UNB. Instituto Federal do Tocantins Campus Palmas - IFTO - TO - Brasil https://orcid.org/0000-0002-5642-6049 http://lattes.cnpq.br/3043820195417966
\end{abstract}

Resumo: O presente trabalho tem como objetivo apresentar reflexões sobre as contribuições da Educomunicação para formação integral, politécnica, diante da nova configuração social, a partir de discussões sobre a importância da dialogicidade no processo de ensino e da criação e desenvolvimento de ecossistema comunicativo, que é uma característica da Educomunicação, vista como uma interface entre Educação e a Comunicação. Ressaltando a importância das práticas educomunicativas na promoção da pluralidade de saberes, diversidade de experiências no contexto escolar e de alternativas para uma educação emancipatória. A metodologia utilizada consistiu em uma revisão bibliográfica. $\mathrm{O}$ trabalho apresenta como conclusão o papel fundamental que a Educomunicação assume na formação de sujeitos nas suas várias dimensões a partir de uma perspectiva comunicacional. A definição de Educomunicação tem como referências os autores Soares e Kaplún. Já as concepções de formação integral são apresentas a luz das ideias de Moura, Lima e Silva, Ramos, Ciavatta, Saviani e Frigotto.

Palavras-chaves: Educomunicação. Formação integral. Dialogicidade. 
GUIMARÃES, CASTILHO, 2019

\begin{abstract}
The present work aims to present reflections on the contributions of Educommunication to integral formation, polytechnics, in face of the new social configuration, based on discussions about the importance of dialogicity in the teaching process and the creation and development of communicative ecosystem, which is a characteristic of Educommunication, seen as an interface between education and communication. Highlighting the importance of educommunication practices in the promotion of a plurality of knowledge, diversity of experiences in the school context and alternatives to emancipatory education. The methodology used consisted of a bibliographic review. The paper presents as a conclusion the fundamental role that Educommunication assumes in the formation of subjects in its various dimensions from a communication perspective. The definition of Educommunication has as references the authors Soares and Kaplún. The conceptions of integral formation are presented in light of the ideas of Moura, Lima and Silva, Ramos, Ciavatta, Savinni and Frigotto.
\end{abstract}

Keywords: Educommunication. Integral formation. Dialogicity.

Resumen: El presente trabajo tiene como objetivo presentar reflexiones sobre las contribuciones de la Educomunicación para formación integral, politécnica, ante la nueva configuración social, a partir de discusiones sobre la importancia de la dialogicidad en el proceso de enseñanza y de la creación y desarrollo del ecosistema comunicativo, que es una la característica de la Educomunicación, vista como una interfaz entre Educación y Comunicación. Resaltando la importancia de las prácticas educomunicativas en la promoción de la pluralidad de saberes, diversidad de experiencias en el contexto escolar y de alternativas para una educación emancipatoria. La metodología utilizada consistió en una revisión bibliográfica. El trabajo presenta como conclusión el papel fundamental que la Educomunicación asume en la formación de sujetos en sus varias dimensiones a partir de una perspectiva comunicacional. La definición de Educomunicación tiene como referencias a los autores Soares y Kaplún. Las concepciones de formación integral son presentadas a la luz de las ideas de Moura, Lima e Silva, Ramos, Ciavatta, Saviani y Frigotto.

Palabras claves: Educomunicación. Formación integral. Dialogicidad. 


\section{Introdução}

A sociedade tem passado por diversas transformações na esfera política, econômica e comunicacional, em virtude dos impactos causados pelas Tecnologias da Informação e Comunicação - TIC, que estão construindo um modelo diferente de sociedade, não mais baseado na produção agrícola ou industrial, mas sim, na produção de informações. Segundo Orozco (2014) a interatividade com as telas não é mais algo que se faça esporadicamente, com a finalidade de buscar informação ou entretenimento, mas uma necessidade. No campo educacional são perceptíveis as mudanças nas formas de ensinar e aprender, tornando ainda mais desafiadora a promoção da formação integral dos educandos, que tem como núcleo básico: a ciência, cultura, tecnologia e trabalho, sendo vista como uma possibilidade de superação da dualidade do sistema educacional brasileiro, que separa formação geral de formação técnica. Além disso, os meios de comunicação incluem às tradicionais dificuldades da escola um novo desafio, ao descentralizarem as formas de difusão e circulação das informações (SARTORI, 2010). Neste panorama, a educação voltada para formação integral, politécnica, tem como prerrogativa a formação de sujeitos emancipados, capazes de entender, ressignificar e transformar a realidade em que vivem.

De acordo com Nascimento (2015) essa emancipação depende da insurgência da "descolonização de mentes" e de uma cultura escolar plural. Na tentativa do fortalecimento dessa pluralidade, ganham destaques práticas educomunicativas, que visam à pluralidade de saberes e diversidade de experiências, tendo como um de seus pilares a promoção de dialogicidade no processo de aprendizagem, como defende Freire (1983) é no diálogo que as relações se constroem e por meio dele que a educação pode ter o papel emancipador e transformador.

Essas práticas educomunicativas são direcionadas pelo novo campo de intervenção social, denominado de Educomunicação, que consiste na interface entre Educação e Comunicação, que como esclarece Soares (2002) pode ser percebida como um conjunto de ações cuja finalidade é integrar às práticas educativas o estudo sistemático dos sistemas de comunicação, criar e fortalecer 
ecossistemas comunicativos em espaços educativos e melhorar o coeficiente expressivo e comunicativo das ações educativas.

Análogo ao ecossistema verde ou biológico, Martín-Barbero (2011) e Soares (2011), apresentam o conceito de ecossistema comunicativo, caracterizado por dois movimentos: o primeiro estabelece uma a relação com as novas tecnologias que dá origem a uma nova experiência cultural, mais tangíveis entre os jovens, o segundo se referes ao surgimento de um ambiente educacional de informação e múltiplos conhecimentos, que vai além da sala de aula escola e do uso do livro didático. São relações construídas coletivamente com estratégias que primam pelo diálogo entre professores, alunos, gestores, pais, toda comunidade escolar.

Para Nascimento (2015) a Educomunicação é um modelo endógeno de educação, ou seja, com ênfase no processo valoriza a transformação do sujeito e de sua comunidade, tendo o educando como protagonista. Com a definição do processo como foco ocorre o rompimento da unidirecionalidade da comunicação, e partir de então, todos os sujeitos envolvidos têm voz e vez. Para exemplificar, podemos citar o educador francês Célestin Freinet, como um dos predecessores na inserção das mídias como instrumento pedagógico nas escolas, os alunos eram incentivados a criar um jornal de divulgação não só nas escolas, mas também além de seus muros. Essa atividade possibilitou, além do diálogo, novas percepções de mundo viabilizadas pelas TICs (BARBEY, 2010).

A área da Educomunicação é recente e, por isso, ressalta-se a necessidade de realizar pesquisas empíricas que construam o conhecimento da área a partir da experiência concreta na escola, com a participação efetiva dos alunos, professores e toda a comunidade escolar. Aqui reside a proposta desde trabalho, que visa apresentar uma revisão de literatura e reflexão crítica, concebido à luz das práticas educomunicativas, como uma potencialidade de cooperação ao trabalho educativo. 


\section{Formação Integral}

Conforme Moura et al. (2015) a formação humana não nasce e nem se encerra no sistema educacional, sendo resultado das relações sociais e de produção e a escola é um local institucionalizado, onde essas relações acontecem. A priori a escola era um luxo possível a poucos, mas no contexto da produção capitalista passou a ser vista como essencial para a sociabilidade humana. Porém como o advento do capitalismo, como explica Saviani (1989) passa a existir a necessidade de universalizar a escola, com intuito de generalizar os códigos e o alfabeto, para atender às necessidades de expansão do capitalismo.

Assim, sobre essa base estruturam-se os currículos escolares, constituído do domínio da Linguagem, da Matemática, das Ciências Naturais e das Ciências Sociais. No entanto, essa generalização do conhecimento sistematizado conta com contradições, visto que a sociedade capitalista desenvolveu um mecanismo, pelo qual ela elabora o conhecimento e repassar em parcela aos trabalhadores, que dominam somente o conhecimento necessário para desenvolver seu trabalho no qual é especialista. Neste panorama, há dicotomia do trabalho em manual e intelectual, instrução técnica e instrução profissional. (SAVIANI, 1989, p. 10). Para Moura et tal. (2015) tal divisão, é resultado de uma estratégia de dominação do capital em formar indivíduos unilaterais.

Diante da dicotomia do processo educacional, surge o conceito de formação integral, politécnica que segundo Ramos et al. (2005) foi introduzido na história da educação brasileira em decorrência de um debate travado na década de 1980 sobre a possibilidade de uma formação básica, que superasse a dualidade entre a cultura geral e cultura técnica.

No que tange à formação integral Ciavatta (2005) apresenta como núcleo básico do currículo integrado: trabalho, ciência e cultura, visando atender às necessidades e características sociais, culturais, econômicas e intelectuais dos estudantes. Para Moura et al. (2015) estaria presente na escola unitária humanista apresentada por Gramsci, que seria uma alternativa à escola tradicional, uma escola desinteressada, essencialmente, humanista, não 
condicionada ao ensino memoristico, mas voltada para o desenvolvimento da sua capacidade de criação intelectual e prática.

Moura et al. (2015) concorda com Marx e Gramsci que a materialização da politecnia e escola unitária, não é possível na sociedade atual, que está sobre a égide do capitalismo. Mas é necessário plantar e cuidar para que cresçam as sementes da formação integral, politécnica e unitária.

Nessa perspectiva, segundo os autores o ensino médio integrado a educação profissional pode ser visto como uma condição necessária na travessia para uma nova realidade, desde que tenham como eixo estruturante o trabalho, ciência e cultura. A necessidade dessa formação profissional ainda no ensino médio, faz-se necessária na realidade brasileira, onde a classe trabalhadora encontra-se mais degradada que nos países do capitalismo avançado. Tendo em vista a extrema desigualdade socioeconômica, que obriga jovens antes dos 18 anos ingressarem no mercado de trabalho para auxiliar a renda familiar garantir sua própria sustentação, assim é um luxo dos estratos médios e altos da sociedade escolher uma profissão somente após 17 ou 18 anos.

Conforme Ramos (2010) as lutas dos educadores progressistas em defesa da escola unitária ganharam mais visibilidade no Brasil na década de 80 , período em que foram intensos os debates sobre os rumos da educação, após o fechamento de um ciclo e ditaduras, a sociedade civil mobilizou-se para a incorporação do direito à educação pública, laica e democrática na Constituição. No que se refere à educação básica, a defesa consistia na instauração de um tratamento unitário que se inclui a educação infantil até o ensino médio, apontando como indispensável a vinculação da educação à prática social e o trabalho como princípio educativo. Compreendendo o trabalho como atividade ontológica, como valor intrínseco a vida humana e ao conhecimento, que ele proporciona na relação com a natureza e como os demais.

Dessa forma, "o trabalho como atividade criadora diferencia-se das formas históricas e alienantes de exploração do trabalhador, constituindo-se como princípio educativo" (CIAVATTA, 2005, p. 8). Na orientação do trabalho como princípio educativo a educação se apresenta como capacidade de conhecer, de atuar de transformar e ressignificar a realidade. 
A educação integral, formadora de sujeitos capazes de transformar a realidade, torna-se possível em um contexto educacional no qual a dialogicidade se faz presente, possibilitando uma comunicação horizontal entre atores do processo educativo. Nessa perspectiva, é possível perceber a importância da Educomunicação, definida como uma interface entre a Comunicação e Educação, e tendo como características: dialogicidade, interdisciplinaridade, gestão participativa e intervenção social.

\section{Educomunicação}

Conforme Kaplún (1984) é intensa a ligação entre as áreas da Educação e Comunicação, que são interdisciplinares e indissociáveis. O autor faz um alerta ao risco da limitação à Comunicação Educativa à mídia; ao estabelecer uma implícita equivalência em virtude da qual, quando enuncia Comunicação, automaticamente se refere a meios e tecnologias de comunicação. Para ele é fundamental ultrapassar esta visão redutora e postular que a Comunicação Educativa abarca certamente o campo da mídia, mas não apenas esta área: abarca também, e em lugar privilegiado, o tipo de comunicação presente em todo processo educativo, seja ele realizado com ou sem o emprego de meios.

"Isso implica considerar a Comunicação não como um mero instrumento midiático e tecnológico, e sim, antes de tudo, como um componente pedagógico". (KAPLÚN,1999, p.68). A Educomunicação, que de acordo com Soares (2002) consiste em um conjunto de ações cuja finalidade é integrar às práticas educativas o estudo sistemático dos sistemas de comunicação, criar e fortalecer ecossistemas comunicativos em espaços educativos e melhorar o coeficiente expressivo e comunicativo das ações educativas.

Para Soares (2000) tanto a educação quanto a comunicação, numa perspectiva de racionalidade moderna, tiveram seus campos de atuação demarcados, no contexto imaginário social, configurando-se como espaços independentes, aparentemente neutros, cumprindo funções específicas. Cabendo à educação administrar a transmissão do saber necessário para o desenvolvimento 
social e a comunicação responsável pela difusão de informações, pelo lazer popular e pela manutenção do sistema produtivo da publicidade.

Porém, na América Latina, uma aproximação entre essas duas áreas foi constatada, em decorrência das contribuições teóricas e práticas de filósofos da educação ou da comunicação e se consolida com o avanço das conquistas tecnológicas e redução de custos dos equipamentos:

No entanto, no mundo latino, certa aproximação foi constatada, graças à contribuição teórico-prática de filósofos da educação como Célestin Freinet ou Paulo Freire, ou da comunicação, como Jesús Martín-Barbero e Mário Kaplún. Colaboraram também para esta aproximação o avanço das conquistas tecnológicas e o barateamento dos custos dos equipamentos, o que levou grupos ativos e organizados de especialistas a iniciarem um irreversível processo de aproximação entre estes dois campos (SOARES, 2000, p.2).

De acordo com Borges e Marques (2016) a Educomunicação recebe também a contribuição imprescindível de outras áreas que pertencem ao universo das Ciências Humanas e Sociais, ampliando, dessa forma, a possibilidade de surgirem novas posturas epistemológicas sobre o campo da Educomunicação. Dessa forma, falar de Educomunicação é falar de práticas sociais e a interação com diversas áreas do conhecimento, logo toda atividade comunicativa é também educativa.

“Os estudos publicados sobre a interface Comunicação/Educação, em sua maioria, ressaltam a práxis como característica essencial ao campo da Educomunicação, definindo-o como uma área concreta de intervenção social" (BORGES; MARQUES, 2016, p. 5). Assim, como esclarece Costa (2015) a Educomunicação proporciona aos cidadãos uma leitura crítica dos meios de comunicação, promovendo formação integral de quem vivência a realidade da sociedade em rede.

\subsection{Educomunicação no Brasil}

De acordo com Soares (2014) nos anos de 1970 os olhos estavam voltados para Inglaterra, Canadá e Austrália, que eram referência em educação midiática, esses países recebiam considerável apoio do governo. Assim como 
ocorreu na França. Já no Brasil, inicialmente, o assunto é encontrado em Organização não Governamentais e em núcleos de pesquisas das universidades, e foi a partir da contribuição deles e da universidade - geradoras de novas orientações e metodologias de trabalho - que a questão da Educação Midiática começou a se aproximar das políticas públicas, como comprova o projeto Nas Ondas do Rádio, desenvolvido pela Prefeitura de São Paulo.

Esses movimentos, por meio de uma perspectiva dialética, com forte influência do educador Paulo Freire, trabalhavam os campos da Educação e Comunicação de forma relacional, visando, entre outros aspectos, aguçar a criticidade dos envolvidos frente às mensagens emitidas pelos meios massivos de comunicação (BORGES; MARQUES, 2016, p.5).

O Núcleo de Comunicação e Educação (NCE) da Universidade de São Paulo (USP), criado em 1986 tem uma importante contribuição no processo de consolidação da Educomunicação no Brasil. O NCE reúne professores de várias universidades brasileiras interessados na interrelação entre Comunicação e Educação. Seu primeiro trabalho foi concluído em 1999, envolvendo especialista de 12 países da América Latina e Países da Penísula Ibérica para investigar o que pensavam os coordenadores de projetos na área e qual o perfil dos profissionais que trabalhavam nesta inter-relação.

No ano de 1998, ocorreu, na cidade de São Paulo, o I Congresso Internacional sobre Comunicação e Educação. Este evento foi voltado para especialistas em educação e profissionais de comunicação, contaram com a participação de 1.500 pessoas, entre eles 170 palestrantes de 30 países. O impacto desde evento teve tanta relevância que se tornou objeto de estudos acadêmicos no Brasil e no exterior, considerado um dos cinco eventos mundiais mais relevantes sobre Mídia e educação da década de 1990, proporcionando o intercâmbio de ideias tanto da Europa quanto da América Latina (CORTEZ et al., 2018).

De acordo com Soares (2008) o resultado da pesquisa revelou que a interface entre Comunicação e Educação havia transformado em integração, com o surgimento de um campo novo e distinto: a Educomunicação, conceito que passou a denominar não apenas um determinado ângulo programático da interação comunicação/educação (o tradicional tema da educação ante os meios), mas foi 
atribuído ao conjunto dos elementos reconhecidos, na prática dos educomunicadores, como constitutivos de um novo modo de se trabalhar a interface.

A pluralidade e abrangência do conceito de Educomunicação possibilitou diversas atuações, como: análise de produção midiática, mediação comunicativa, expressão comunicativa através das artes e gestão de comunicação. Tal fato, como afirma Soares (2008), fez com que ela ganhasse estrada no Brasil, mobilizando empreendedores culturais, comunicadores, educadores e especialmente estudantes de todos os níveis, tornando-se, aos poucos, referência para políticas públicas.

\section{Contribuições da Educomunicação para formação Integral}

“O processo educomunicacional é um espaço fecundo para reflexão sobre a vida e construção de identidade políticas-reflexivas essenciais para formação integral do sujeito, tanto para o educomunicador como para o estudante" (NASCIMENTO, 2015, p. 56). Nesse sentido, o educomunicador configura-se como um sujeito, que na construção de um projeto educomunicativo problematiza as escolhas do educando, para exemplificar essa afirmação, Nascimento (2015) cita como exemplo na elaboração de um jornal escolar, na qual podem surgir questionamentos como: Que sentido os textos podem produzir? Por que utilizar determinada fotografia? Por que a escolha de uma dada pauta e não de outra?

Nascimento adianta, também, que a compreensão da dialogicidade no processo educomunicativo para além da relação educador e educando, a Educomunicação se apresenta como teia de relações (ecossistemas). Dessa forma, ela tem como característica a criação e o desenvolvimento de "ecossistemas comunicativos", conceito empregado por Soares (2011) como figura de linguagem para nomear uma ideia de relações, construído coletivamente em determinado espaço, como resultado de uma decisão estratégica de favorecer o diálogo social, considerando, inclusive as potencialidades dos meios de comunicação e de suas tecnologias. São as regras determinadas e rigorosamente seguidas que determinam o tipo de ecossistema 


\title{
Educomunicação: proporcionando ações
} formativas para educação integral

GUIMARÃES, CASTILHO, 2019

comunicativo. No caso da Educomunicação, como maneira própria de relacionamento, Soares (2011) afirma que se faz a opção por modalidades abertas e criativas de relacionamento, possibilitando que as normas que regem o convívio passar a reconhecer a legitimidade do diálogo como metodologia de ensino, aprendizagem e convivência.

Soares (2011) defende que um ambiente escolar educomunicativo elementos da pedagogia da comunicação:

\begin{abstract}
Um ambiente escolar educomunicativo caracteriza-se, justamente, pela opção de construtores pela abertura à participação, garantindo, não apenas a boa convivência entre as pessoas (direção-docentesestudantes), mas, simultaneamente, um efetivo diálogo sobre às práticas educativas (interdisciplinaridade, multidisciplinaridade, pedagogia de projetos) elementos que confortam a "pedagogia da comunicação" (2011, p. 15).
\end{abstract}

O autor destaca, ainda, que no que se refere ao ecossistema comunicativo no espaço do ensino médio, ele consiste em um projeto educativo que tem como meta a qualidade dos relacionamentos e busca de resultados mensuráveis, firmados a partir de uma proposta comunicativa negociada no âmbito da comunidade educomunicativa.

Nesse sentido, a Educomunicação pode ser percebida como transversal no currículo do ensino médio, "na perspectiva da educação para a vida, do sabor da convivência, da construção da democracia, da valorização dos sujeitos, da criatividade, da capacidade de identificar para que serve o conjunto dos conhecimentos compartilhados por meio da grade curricular" (SOARES, 2011. p, 45).

Próspero (2017) garante que a Educomunicação trabalha a partir de uma perspectiva transdisciplinar. O princípio é considerado, essencialmente, para o tratamento de assuntos complexos no âmbito dos denominados "temas transversais", como saúde, multiculturalidade, ética, meio ambiente, entre outras, que são fundamentais de serem abordados numa perspectiva de educação integral.

Sousa (2016) comunga com os pressupostos de Soares (2011) e Próspero (2007) e acrescenta que as ações educomunicativas não são a salvação da educação, mas servem para elaborar algumas saídas para um ensino que emancipa. A partir de então, é fundamental entender como se dá a comunicação 
no ambiente escolar e como essas práticas pedagógicas educomunicativas estimulam o diálogo da comunidade escolar.

Conforme Borges e Marques (2016) algumas iniciativas têm contribuído para o fortalecimento do campo da Educomunicação, que embora seja relativamente novo, ganha espaço nas discussões teóricas e práticas em torno da inter-relação Comunicação/Educação. Uma dessas iniciativas, foi a adoção de metodologias educomunicativas em programas do Governo Federal, como o Mais Educação (PME) em 2014, tendo como estratégia do Governo induzir a ampliação da jornada escolar, oferecendo às escolas a possibilidade de criarem e fortalecerem ecossistemas comunicativos, estimulando práticas de socialização e convivência e a organização curricular, na perspectiva da Educação Integral. Além disso, práticas educomunicativas tornaram-se políticas públicas em São Paulo, por meio da lei n ${ }^{\circ} 13.941$ e em Mato Grosso do Sul com a lei $n^{\circ} 8.889 / 08$.

$\mathrm{Na}$ esfera acadêmica, é possível perceber uma relevante produção de artigos, monografias e dissertações e algumas teses, que abordam a perspectiva educomunicativa. Soma-se a isso, o fato do Brasil contar com duas graduações em Educomunicação: a licenciatura, criada pela USP em 2009; e o Bacharelado em Comunicação Social, com habilitação em Educomunicação, criado nesse mesmo ano pela Universidade Federal de Campina Grande (UFCG), na Paraíba.

\section{Considerações finais}

Nesse trabalho, buscou-se considerar as contribuições da Educomunicação como instrumento de formação integral, baseadas no diálogo e na participação e não exige somente tecnologias, mas também mudanças de atitudes e de concepções. Ressaltou-se a importância da dialogicidade dos produtos culturais da mídia como um processo intercambiado dos saberes, com possibilidade de construções críticas, criativas e reflexivas. Por toda essa intervenção na vida social, os processos comunicacionais devem ser avaliados na perspectiva inter/transdisciplinar.

A partir da revisão bibliográfica foi possível concluir que a Educomunicação é um campo de intervenção social, que apresenta como pilares 


\section{Educomunicação: proporcionando ações}

formativas para educação integral

GUIMARÃES, CASTILHO, 2019

concepções similares àquelas defendidas pelo ideário de formação integral, ou seja, a formação de sujeitos em suas várias dimensões, capazes de compreenderem o contexto em que estão inseridos e promoverem mudanças comprometidas com uma sociedade mais humana e com mais justiça social.

No percurso rumo a essa formação, as práticas educomunicativas, que visam à pluralidade de saberes e diversidade de experiências, têm um importante papel, uma vez que ao fortalecer a expressão e ecossistema comunicativo escolar, ela proporciona uma maior dialogicidade no processo formativo, sendo por meio do diálogo que as relações se constroem e que a educação pode ter seu papel transformador.

Diante das discussões apresentadas é possível afirmar que há uma relação sinérgica entre a Educomunicação e a perspectiva de formação integral, no sentindo de promover mudanças reais para educação. Assim, é cada vez mais necessária a realização de trabalhos que discutam a importância dessa relação e possam fortalecer a reflexão epistemológica sobre ela.

\section{REFERÊNCIAS}

BARBEY, Francis. L'Èducation aux médias: de l'ambiguité du concept aux défis d'une pratique éducative. Paris: Publibook, 2010.

BONIN, J. CORREA,F. Práticas educomunicativas no projeto Alunos em Rede Mídias Escolares e cidadania comunicativa . comunicação \& educação • Ano XX • número 1 - jan/jun 2015. Disponível em: http://www.revistas.usp.br/comueduc/article/view/81250/96717. Acesso em: 09 de set. 2018. https://doi.org/10.11606/issn.2316-9125.v20i1p29-37

BORGES, J. S. MARQUES, P. P. Educomunicação: origens e conexões de uma nova área do conhecimento. III Congresso Nacional de Educação. Bahia. 2016.

CIAVATTA, Maria; A formação integrada: a escola e o trabalho como lugares de memória e de identidade. p. 83 a 105. In FRIGOTTO, Gaudêncio; CIAVATTA, Maria; RAMOS, Marise (orgs.). Ensino médio integrado: concepção e contradições. São Paulo: Cortez, 2005. https://doi.org/10.22409/tn.3i3.p6122

CORTES, Tanisse Paes Bóvio Barcelos; MARTINS, Analice de Oliveira; SOUZA, Carlos Henrique Medeiros de. Educação midiática, educomunicação e formação docente: parâmetros dos últimos 20 anos de pesquisas nas bases scielo e scopus. Educ. rev., Belo Horizonte, v. 34, 2018. https://doi.org/10.1590/0102-4698200391 


\section{Educomunicação: proporcionando ações}

formativas para educação integral

GUIMARÃES, CASTILHO, 2019

COSTA, K. E. C. Educomunicação: campo, interdisciplinaridade e formação. In: $3^{\circ}$ Congresso Literacia, Media e Cidadania - Portugal, abril, 2015. Disponível em: http://www.lasics.uminho.pt/ojs/index.php/cecs_ebooks/article/view/2243. Acesso em: 20 de set. 2018

FREIRE, Paulo. Educação e Mudança. Ed. Paz e Terra: Rio de Janeiro, 1983.

FRIGOTTO, Gaudêncio; CIAVATTA, Maria; RAMOS, Marise (orgs.). Ensino médio integrado: concepção e contradições. São Paulo: Cortez, 2005. Cap. 1 e 2. p. 21 a 82.

KAPLÚN, M. Processos educativos e Canais de Comunicação. In: Revista Comunicação e Educação. São Paulo. 1999. https://doi.org/10.11606/issn.23169125.v0i14p68-75

MARTÍN-BARBERO, Jesús. Desafios culturais da comunicação à educomunicação. In: CITELLI, Adilson Odair; COSTA, Maria Cristina Castilho (Orgs.). Educomunicação: construindo uma nova área de conhecimento. São Paulo: Paulinas, 2011.

MOURA, Dante Henrique; LIMA FILHO, Domingos Leite; SILVA, Mônica Ribeiro. Politecnia e formação integrada: confrontos conceituais, projetos políticos e contradições históricas da educação brasileira. Revista Brasileira de Educação, v. 20, n. 63, p. 1057-1080, 2015. Disponível em: http://www.scielo.br/pdf/rbedu/v20n63/1413-2478-rbedu-20-63-1057.pdf. https://doi.org/10.1590/s1413-24782015206313

NASCIMENTO, M. L. Educação Integral e o paradigma da educomunicação: um estudo sobre o mais educação nas escola de Santa Maria. Dissertação (Mestrado em Comunicação). Universidade Federal de Santa Maria. Santa Maria. 2015. https://doi.org/10.26512/2015.05.d.19166

OROZCO GÓMEZ, Guillermo. Entre telas: novos papéis comunicativos e educativos dos cidadãos. In: APARICI, Roberto (Org.). Educomunicação: para além do 2.0. São Paulo: Paulinas, 2014.

PRÓSPERO, D. A Educação Integral na perspectiva da Educomunicação: a implementação no Programa São Paulo Integral. In SOARES, Ismar; VIANA, Claudemir; XAVIER, Jurema (orgs). Educomunicação e suas áreas de intervenção: novas paradigmas para o diálogo intercultural. https://doi.org/10.11606/d.27.2013.tde-30012014-105832

RAMOS, Marise. Ensino Médio Integrado: ciência, trabalho e cultura na relação entre educação profissional e educação básica. Cap. 2 p. 42 a 58 In MOLL, Jaqueline et al. Educação profissional e tecnológica no Brasil contemporâneo: desafios, tensões e possibilidades. Porto Alegre: Artmed, 2010. https://doi.org/10.1590/s0101-73302010000300012

SARTORI, Ademilde Silveira. Educomunicação e sua relação com a escola: a promoção de ecossistemas comunicativos e a aprendizagem distraída. Comunicação, mídia e consumo, São Paulo, v. 7, n. 19, p. 33-48, 2010. 
SAVIANI, D. Sobre a Concepção de Politecnia. Ministério da Saúde. Fundação Oswaldo Cruz. Rio de Janeiro, 1989. https://doi.org/10.5327/z16794435201917s1009

SOARES, I. Educomunicação: o conceito, o profissional, a aplicação: contribuições para a reforma do ensino médio. São Paulo: Paulinas, 2011.

SOARES, I. O. E quando o educador do ano é um educomunicador? In: Comunicação e educação. São Paulo. 2008. https://doi.org/10.11606/issn.23169125.v13i3p39-52

SOARES, I. O. Educação à distância como prática educomunicativa: emoção e envolvimento na formação continuada de professores da rede pública.. Revista USP, 55(set/nov). São Paulo. 2002. https://doi.org/10.11606/issn.2316-9036.v0i55p56-69

SOARES, I. O. Educomunicação e Educação Midiática: vertentes históricas de aproximação entre Comunicação e Educação. Revista Comunicação e Educação. Ano XIX, no 2. São Paulo. 2014. https://doi.org/10.11606/t.27.2018.tde-03122018-144842

SOARES, I. O. Educomunicação o conceito, o profissional a aplicação: contribuições para a reforma do ensino médio. Paulinas. 2011.

SOUZA, G. S. Educomunicação e protagonismo juvenil: contribuições de uma rádio escolar. Dissertação (Mestrado em Educação). Universidade do Estado de Santa Catarina. Santa Catarina. 2016. https://doi.org/10.5327/z2176-947820180272

Data Recebimento: 05/06/19

Data Aprovação: 03/07/19 